\title{
Actividade Física Adaptada: uma visão crítica
}

\author{
Urbano Moreno Marques \\ José Alberto Moura e Castro \\ Maria Adília Silva \\ Faculdade de Ciências do Desporto e de Educação Física, Universidade do Porto
}

https://doi.org/10.5628/rpcd.01.01.73

\section{INTRODUÇÃO}

A filosofia subjacente de orientação da educação da pessoa com deficiência, nos tempos recentes tem levado a que as grandes linhas de investigação apontem para a maior autonomia da pessoa com deficiência.

Neste contexto, julgamos que as respostas encontradas levam a procurar uma maior participação da pessoa com deficiência na sociedade. Contudo a referida participação tem sido abordada no sentido de uma colaboração e não de uma efectiva participação interventiva. Este aspecto, é devido em parte, ao facto que a pessoa com deficiência não ter sido chamada para contribuir nesse mesmo processo. Em nosso entender o direito de opção, de escolha e de intervenção por parte da pessoa com deficiência, é fundamental.

Nesta perspectiva, a pessoa com deficiência tem que ser chamada a contribuir com o seu saber empírico, isto é, a dar sua própria opinião.

Por outro lado os investigadores até à década de 80 estudavam os assuntos fechados na sua área de saber. Hoje tenta-se abordar os mais variados aspectos de estudo conjugando várias áreas de investigação, fazendo cair as barreiras e, assim, enriquecer as respostas. Este facto, leva à existência de interfaces das áreas do saber académico e profissional, que em nosso entender vão ajudar de uma maneira decisiva a resolver aspectos que até ao momento não o foram como a homogeneidade da terminologia, da limitação da população alvo, da metodologia de ensino que deve ser partilhada de uma maneira uniforme, de estudos das provas e aparelhos para avaliar a pessoa com deficiência nas diferentes vertentes e das ajudas técnicas para a vida diária, do ensino, do desporto e da Educação Física. Especificamente em relação à área do desporto pensamos que os aspectos menos estudados são o treino desportivo, as técnicas de intervenção, e as próprias modalidades.

A organização da actividade desportiva continua a ser debatida no sentido de procurar a maneira mais correcta de definir os locais de prática e com quem deve ser realizada. A classificação desportiva também continua a ser polémica sendo, no entanto, um dos temas que mais tem sido abordado pelos estudiosos. As áreas mais recentes de estudo e que começa a preocupar os investigadores nas seus mais variados aspectos são a Terceira Idade, aspectos patológicos, e a Recreação e Tempos Livres de pessoas com deficiência.

\section{EVOLUÇão}

A actividade física para a pessoa com necessidades especiais tem vindo a ser alvo das mais variadas atenções. Exemplo disso é a Carta Europeia do Desporto para Todos: as Pessoas Deficientes (1988), do Conselho da Europa, que reconhece a actividade física como "um meio privilegiado de educação, valorização do lazer e integração social”(2).

Potter, como elemento do Comité para o Desenvolvimento do Desporto do Conselho da Europa, define esta actividade física como uma gama completa de actividades adaptadas às capacidades de cada um, particularmente ao desenvolvimento motor, à Educação Física e a todos as disciplinas desportivas (14).

Por outro lado, vários autores $(3,8,18)$ consideram que a actividade física adaptada (na medida em que se aplica a pessoas sem possibilidades de a 
praticarem em condições normais) está limitada aos indivíduos deficientes reconhecidos pela Organização Mundial de Saúde (12) e expressa-se em três dimensões, designadamente a competitiva, a recreativa e a terapêutica. A estas vertentes acrescentou o Comité para o Desenvolvimento do Desporto, em $1981^{(1)}$, a educativa. De salientar que idêntica concepção nos apresenta a Federação Portuguesa de Desporto para Deficientes (4). Contudo, observamos, segundo as conclusões do Seminário "A recreação e lazer da população com necessidades especiais" (Faculdade de Ciências do Desporto e de Educação Física da Universidade do Porto, 2000), que as dimensões competitiva, educativa e terapêutica prevalecem sobre a recreativa. Porém, estamos hoje muito longe, neste campo da reabilitação, do que aconteceu nos primórdios da humanidade e nos primeiros séculos da civilização. Segundo Lowenfeld e Kirk e Gallagher podemos reconhecer quatro grandes períodos de desenvolvimento das atitudes em relação aos indivíduos com necessidades especiais, os quais correspondem a fases distintas da história $(6,9)$.

\section{$1^{\circ}$ Período: Separação}

$\mathrm{Na}$ maioria das sociedades primitivas o deficiente era visto com superstição e malignidade. Nesta época o conhecimento centrava-se no pensamento mágico-religioso, o qual explicava e continua a explicar muitos dos acontecimentos do dia-a-dia do homem primitivo.

Já no início da Idade Média foi aceite uma relação de causalidade entre demonologia e anormalidade (7). Posteriormente, este sentimento de horror em relação à deficiência foi dando lugar ao sentimento de caridade, o qual corresponde ao início da era da protecção.

\section{$2^{\circ}$ Período: Protecção}

Esta concepção apareceu com o desenvolvimento das religiões monoteístas. Fundaram-se asilos e hospitais onde os deficientes eram recolhidos. No entanto era ainda prática comum mutilar ou cegar indivíduos que cometiam graves delitos.

Nos finais da Idade Média, através das ordens religiosas, foram criados vários hospícios onde os deficientes eram assistidos, basicamente em questões de alimentação e vestuário. Acreditava-se, ainda, que tratando bem os deficientes, os idosos e outros carenciados se obtinha um lugar no céu. Com o aparecimento do movimento reformista da Igreja surge uma nova visão sobre os deficientes. Passaram a ser encarados como um indício do descontentamento divino, sendo novamente relegados para um plano inferior. Só mais tarde começaram a surgir as primeiras tentativas ao nível da sua educação, as quais traduzem já o início do $3^{\circ}$ período.

\section{$3^{\circ}$ Período: Emancipação}

Com o novo interesse criado pelo Renascimento em estudar o homem, a industrialização e a consequente falta de mão de obra, bem como o aparecimento de deficientes ilustres, nomeadamente cegos, foi dado um grande impulso na sua educação, influenciando decisivamente os pioneiros da Educação Especial. Assim, foi necessário chegarmos ao último quartel do século XVIII, com o surgimento das ideias iluministas da Revolução Francesa, para que os problemas da deficiência começassem a ser encarados e encaminhados por uma via mais racional e mais científica (16).

Foram sobretudo alguns médicos da escola francesa, como Esquirol e Morel, e alguns médicos da escola alemã, como Griesinger e Kretschmer, que tiveram o mérito de chamar a atenção para a necessidade de os problemas da deficiência passarem a ser observados à luz de novos factos científicos de carácter psicofisiológico e etiopatogénico (5).

Por conseguinte, é o ano de 1801, com Itard e a sua primeira tentativa para educar um deficiente (Victor, o selvagem de Avignon), que é apontado como o início da Educação Especial propriamente dita (13). No entanto, só mais tarde, com o aparecimento da Lei da Educação Obrigatória para Todos, o problema da educação da criança deficiente começa a ser verdadeiramente questionado.

Já nos finais do século XIX a Educação Especial caracterizava-se por um ensino ministrado em escolas especiais em regime de internato, específicas de cada deficiência (escolas que se destinam ao atendimento de crianças e jovens deficientes visuais, auditivos, intelectuais, motores e autistas), embora existissem defensores do sistema integrado (apoio 
prestado a crianças e jovens com problemas educativos especiais inseridos a tempo total ou parcial em classes regulares, visando a sua integração escolar, familiar e social) e fossem aparecendo outras formas de atendimento como o semi-internato, a classe de aperfeiçoamento e a classe especial (classe que funciona no edifício de uma escola regular, mantendo-se os alunos nessa mesma classe durante todo o tempo lectivo). Aparecem as primeiras tentativas de explicação e classificação dos diferentes tipos de deficiência, bem como os primeiros estudos científicos nesta área. E é nesta fase de grande optimismo e desenvolvimento que surge o quarto período, ou seja, a etapa da integração.

\section{$4^{\circ}$ Período: Integração}

O conceito de integração, já defendido por alguns autores nos finais do século XIX, é finalmente posto em prática em pleno século XX. Este confere ao deficiente as mesmas condições de realização e de aprendizagem sócio-cultural dos seus semelhantes, independentemente das limitações ou dificuldades que manifesta.

A segunda metade do século XX caracterizou-se, entre outros aspectos, por um certo desafio que o conceito de normalização trouxe à sociedade. Wolfensberger definiu normalização como sendo a "utilização de meios tão adequados, quanto possível, para estabelecer ou para manter comportamentos e características que são de natureza cultural"(20). Para Mikkelsen, "normalização não significa tornar normal o diferente, mas sim criar condições de vida semelhantes às dos outros elementos da sociedade, utilizando para o conseguir uma grande variedade de serviços existentes nessa mesma sociedade"(11). No entanto, a ideia principal contida no conceito de normalização encontrava-se já subjacente, desde 1948, na Declaração Universal dos Direitos do Homem, quando aí se afirma o "direito de todas as pessoas, sem qualquer distinção, ao casamento, à propriedade, a igual acesso aos serviços públicos, à segurança social e à efectivação dos direitos económicos, sociais e culturais".

Segundo Sousa, "temos de criar as condições para atingirmos as metas da "total participação" e da «igualdade de oportunidades» para as pessoas deficientes, proporcionando-lhes o seu direito de compartilharem a vida social normal da comunidade na qual vivem e de usufruírem as condições de vida semelhantes às de qualquer outro cidadão"(17).

A igualdade que se pretende, como ponto de partida e como meta, não deverá ser entendida como sinónimo de normalização absoluta. A igualdade terá de ser construída através da afirmação do direito à diferença. Com isto pretendemos dizer que devemos criar situações o mais variadas possível para que indivíduos ditos normais e em cadeira de rodas, por exemplo, tenham as mesmas possibilidades. Construir um edifício com larguras de portões diferentes é criar a igualdade de acesso a todos, isto é, para haver igualdade têm de existir diferenças. É neste contexto que aparece, com a Declaração de Salamanca, em 1994, o quinto e último período (por nós considerado), ou seja, a inclusão.

\section{$5^{\circ}$ Período: Inclusão}

O conceito de escola inclusiva teve a sua origem na Declaração Universal dos Direitos do Homem (1948), na Conferência Mundial sobre Educação para Todos (1990) e nas Normas das Nações Unidas sobre a Igualdade de Oportunidades para as Pessoas com Deficiência, de 1993.

No entender de Mayor, a conferência mundial sobre necessidades educativas especiais ao adoptar a Declaração de Salamanca sobre os princípios, a política e as práticas na área das necessidades educativas especiais "inspirou-se no princípio da inclusão e no reconhecimento da necessidade de actuar com o objectivo de conseguir escolas para todos, isto é, instituições que incluam todas as pessoas, aceitem as diferenças, apoiem a aprendizagem e respondam às necessidades individuais"(10).

Assim sendo, as sociedades contemporâneas distinguem-se, em grande parte das anteriores, pela afirmação do respeito pela dignidade humana e pela garantia de que ao portador de qualquer necessidade especial lhe será permitido integrar-se nas diversas metas do funcionamento social sem qualquer barreira psicológica ou física.

Aliás, é essa uma das exigências da nossa actual Constituição.

Concretamente, para estes indivíduos deverão ser 
proporcionadas condições que lhes permitam atingir as seguintes metas (5):

- cuidar de si;

- tornar-se independente no quotidiano;

- participar na vida familiar e em actividades de tempos livres;

- manter contactos sociais;

- obter rendimento nos estudos e no trabalho;

- manter relações afectivas e vida sexual;

- poder assumir o papel de progenitor.

Podemos dizer, numa linguagem simplista, que é através da segurança social, da educação, da formação profissional e do emprego, entre outros, isto é, da reabilitação, que essas condições poderão ser desenvolvidas e que poderá ser encontrado o verdadeiro enquadramento da pessoa com necessidades especiais na sociedade.

Postas as coisas deste modo, devemos actuar, por um lado, ao nível da prevenção e, por outro, assegurar a cada pessoa o usufruto de todo e qualquer serviço de reabilitação, sempre com o espírito de que o meio social faz parte integral do processo.

Todavia, a palavra reabilitação não teve sempre o mesmo significado ao longo da história da humanidade.

A prática tradicional considerou-a como sendo um modelo de terapias e serviços destinados às pessoas deficientes, numa estrutura institucional, muitas vezes sob a égide da autoridade médica.

Esta situação tem sido gradualmente substituída por programas que, embora continuem a prestar serviços médicos, também contemplam serviços sociais e pedagógicos qualificados.

Para a organização Reabilitação Internacional, o conceito de reabilitação deve ser entendido como "um processo em que o uso combinado e coordenado de medidas médicas, sociais, educacionais e vocacionais, permite aos indivíduos com deficiência alcançar níveis de funcionamento o mais elevados possível e, em simultâneo, se integrarem socialmente"(15).

Em Portugal, em Maio de 1989, é proclamada a Lei de Bases da Prevenção e da Reabilitação e Integração das Pessoas com Deficiência (Lei nº9/89), a qual concebe a reabilitação como sendo "um processo global e contínuo destinado a corrigir a deficiência e a conservar, desenvolver ou restabelecer as aptidões e capacidades da pessoa para o exercício de uma actividade considerada normal. Engloba um conjunto variado de acções de prevenção, de reabilitação médico-funcional, de educação especial, de reabilitação psico-social, de apoio sócio-familiar, de acessibilidade, de ajudas técnicas, de cultura, de desporto e de recreação, entre outras, que se destinam ao deficiente e que visam favorecer a sua autonomia pessoal".

Assim, reabilitar perdeu o seu significado restrito de "habilitar de novo". Do tornar o deficiente capaz de realizar novamente uma tarefa, passou a reabilitação a ser encarada como um processo que visa a integração total da pessoa com necessidades especiais.

Por outro lado, a educação especial acompanhou muito de perto a evolução do conceito de deficiência. Começou com características essencialmente assistenciais, desenvolveu-se ao longo dos tempos e hoje procura manter o indivíduo em processos educativos normalizados, através da sua integração. Este conceito de inclusão só será significativo quando for entendido como a solução, não necessariamente exclusiva mas prioritária, cujo âmbito deve ser progressivamente alargado. Não porque ele seja um fim em si mesmo, mas por ser a chave da futura integração dos portadores de necessidades especiais na sociedade.

Este último aspecto é muito importante, visto sabermos que todos os cientistas da área da Antropologia são unânimes em afirmar que o ser humano só se desenvolve no meio dos seus semelhantes. A educação especial foi definida pela UNESCO como sendo "aquela dos que se desviam física ou mentalmente, emocional ou socialmente dos grupos relativamente homogéneos do sistema regular de educação, de modo que é necessário tomar providências especiais para corresponder às suas necessidades"(19).

Presentemente, pode-se dizer que o objectivo fundamental da educação especial é permitir ao indivíduo com necessidades especiais um desenvolvimento máximo das suas aptidões intelectuais, escolares e sociais, originando, desse modo, a integração de todos os cidadãos na vida em comunidade. 
Verificamos nas últimas décadas, devido a mudanças da sociedade e da vontade política dos órgãos de poder, um desenvolvimento da educação especial tanto a nível quantitativo (número de serviços oficiais e privados, número de professores, técnicos especializados e alunos apoiados, orçamentos envolvidos, etc.) como qualitativo (novas tecnologias, formação superior de professores, grande diversidade e melhor apetrechamento dos serviços).

Toda esta evolução deve-se não somente ao avanço tecnológico e da medicina, mas também ao aumento da legislação, à intervenção precoce, à implementação da educação pré-primária, ao prolongamento da escolaridade obrigatória e ao importante papel desempenhado pelas famílias que vêm reivindicando, ao longo do tempo, uma melhoria do atendimento a esta população. Actualmente, tudo aponta para que tendo o aluno necessidades educativas especiais, ou não, não existam diferenças significativas quanto aos objectivos escolares finais, com excepção daqueles que tiverem maiores dificuldades de aprendizagem, os quais poderão ser encaminhados para a frequência de currículos adaptados ou alternativos. Com a aquisição de autonomia e independência criaram-se as condições para a integração do aluno com necessidades educativas especiais no sistema educativo regular, o qual deve estar apto a receber todas as crianças em idade escolar e não apenas algumas (escola inclusiva).

A participação de todos não é apenas desejável do ponto de vista social e moral, mas também do ponto de vista funcional. Assim sendo, o melhor caminho a seguir tem que ser encontrado por todos nós.

\section{OBJECTIVAÇÃO}

Os trabalhos realizados por este Gabinete (monografias, dissertações de mestrado e trabalhos de docentes, entre outros) demonstram uma cobertura alargada de várias áreas.

Através de uma leitura QUALITATIVA E QUANTITATIVA dos 232 trabalhos dos últimos dez anos, por categoria, tentamos encontrar as principais conclusões e a linha evolutiva recolhida pela frequência e dimensão anual dos trabalhos. Parece claro que existem três grandes áreas de preocupações:
- Terminologia e conceitos

- Definição da população com Necessidades Especiais e relação desta com a Actividade Física Adaptada

- Problemas do desporto (vertente do ensino, da competição e da recreação).

A terminologia e os conceitos foram estudados seguindo a evolução internacional, que considera Actividade Física Adaptada como a designação mais consensual (internacional e nacional).

Os conceitos que emergem da Declaração de Salamanca e trabalhos posteriores, apontam para a designação Necessidades Especiais, abrangendo toda a população, independente da idade, que apresenta problemas de acesso a um qualquer sistema social, nomeadamente escolar e desportivo.

Têm ainda sido estudadas as condições da inclusão (escolar e desportiva), condições de acesso e de adesão ou afastamento do desporto de indivíduos com necessidades especiais e a formação necessária e suficiente dos profissionais da área.

Uma preocupação complementar tem sido a análise da legislação (conteúdo e omissões), bem como da sua implementação e interpretação local.

$\mathrm{Na}$ área da definição da população com Necessidades Especiais e a aplicação da Actividade Física Adaptada, emergem as preocupações com os aspectos classificativos, tendencialmente criticando a classificação médico-psicológica e propondo classificações com suporte pedagógico.

Sublinha-se a cobertura efectuada por revisões bibliográficas, de um grande número de patologias e o papel da actividade física (na prevenção e reabilitação), concluindo todos os trabalhos da importância da actividade física e da necessidade de se efectuarem estudos no terreno.

Uma outra linha que tem surgido mais recentemente é a que se refere à qualidade de vida da população com Necessidades Especiais e da sua relação com a saúde. Aparecem também com grande frequência os estudos da relação entre a necessidade especial e o rendimento (académico e/ou desportivo).

Dizendo respeito à área específica do desporto, verifica-se uma preocupação diversificada com a avaliação motora (formal e informal, classificativa ou avaliativa), gerando-se o consenso da sua imperiosa necessidade efectuada com rigor e sem preconceitos. 
Vários trabalhos procuraram verificar as melhores condições e os programas mais eficazes para o ensino de áreas específicas, bem como estudar a aptidão física de vários tipos de população.

Efectuaram-se trabalhos sobre aplicações específicas do ensino de algumas modalidades desportivas e os problemas relacionados com a competição.

Mais recentemente foram aparecendo vários trabalhos dirigidos à recreação, sua importância e formas organizativas, tendo-se verificado que existe ainda uma aderência baixa, estudando-se as razões e concluindo-se pela grande relevância e futuro desta área para a população com Necessidades Especiais. Foram estudadas as condições de acessibilidade dos deficientes a vários locais desportivos, verificando-se que existem maioritariamente estruturas que dificultam ou mesmo inviabilizam a prática desportiva.

Realizaram-se trabalhos sobre áreas psicológicas condicionantes do sucesso participativo no desporto, parecendo que as diferenças da restante população não são problemáticas sendo o desporto um excelente meio de promoção do sucesso psicológico. Verifica-se a realização de alguns trabalhos vocacionados para o aprofundamento de modalidades desportivas específicas (boccia, goalball, basquetebol em cadeira de rodas, entre outras).

Embora em número reduzido existem trabalhos de índole mais restrito da reabilitação, designadamente no contexto terapêutico.

Finalmente foram realizados três trabalhos comparando a situação portuguesa com a de outros países (Espanha, Moçambique e Bélgica).

\section{CONCLUSÕES}

Apesar do consenso sobre os principais conceitos da área NECESSIDADES ESPECIAIS, INCLUSÃO E ACTIVIDADE FÍSICA ADAPTADA, mantem-se em vigor e utilização corrente e oficial, um conjunto de termos e de conceitos, numa amalgama pouco animadora e tendencialmente propiciadora de confusões.

Com efeito, são termos de utilização habitual entre outros, deficientes, desporto adaptado ou para deficientes, integração, educação especial, portadores de deficiência, bem como combinações destes termos. Mais confuso se torna a utilização indiscriminada desta terminologia porque entendida como sinónimos de outros conceitos e não como subdivisões específicas da área.

As Necessidades Especiais representam um alargamento do conceito Necessidade Educativas Especiais, sendo este mais restrito e exclusivamente dirigido ao sistema escolar.

A Inclusão que representa uma revisão do conceito de integração, coloca o ênfase na aceitação da diferença e não na acentuação e discriminação pela diferença. A Actividade Física Adaptada sublinha e congrega todas as formas de participação desportiva de um qualquer indivíduo, mesmo com fortes limitações da capacidade de movimento, e seja qual for o objectivo dessa actividade (educativo, recreativo, competitivo ou terapêutico).

Ao considerar diferentes patologias entende-se estas como limitadoras da normal actividade física e procura-se conhecer a relação positiva da actividade física com uma qualquer forma de prevenção. Podese concluir da urgência de serem efectuados estudos de terreno, a partir das revisões bibliográficas efectuadas que mencionam unanimemente a relevância da actividade física adaptada.

Embora já existam vários trabalhos sobre modalidades específicas e/ou adaptadas, bem como sobre a iniciação desportiva (escolar e competitiva), parece ser claramente insuficiente a produção científica realizada. Recomenda-se a elaboração de trabalhos por modalidade e tipo de necessidade especial, à semelhança dos que já existem sobre boccia/paralisia cerebral e goalball/deficiência visual. Uma preocupação recente sobre a qualidade de vida relacionada com a saúde mostra a interdependência destes factores em populações com necessidades especiais, mas indica-nos também uma preocupante falta de participação, suas causas e motivos. Parecenos poder concluir da importância de serem efectuados mais estudos neste domínio.

Os trabalhos feitos sobre acessibilidades são ainda escassos ou muito antigos, mas apontam inúmeras lacunas, pelo que se pode concluir da urgência de se efectuarem mais trabalhos neste sector. Os trabalhos de natureza psicológica (como por exemplo o estudo de: motivação, interesses, relação entre a proficiência motora e o rendimento escolar e ansiedade) são pouco conclusivos mas fornecem 
indicadores importantes, pelo que devem ser ampliados e replicados em diferentes condições, locais e tipos de população estudada.

Muito recentemente foram feitos os primeiros trabalhos sobre recreação para populações com necessidades especiais, podendo desde já, concluir como uma vertente de grande futuro pelo seu impacto positivo na qualidade de vida e o ainda escasso envolvimento qualitativo e quantitativo. Parecem ser lacunas a rever os poucos estudos sobre aspectos técnicos, treino desportivo e materiais e equipamentos.

\section{REFERÊNCIAS BIBLIOGRÁFICAS}

1. Comité pour le Développement du Sport (1981). Sport pour les Handicapés. Strasbourg: Conseil de l'Europe

2. Conselho da Europa (1988). Carta Europeia do Desporto para Todos: as Pessoas Deficientes (Desporto e Sociedade Antologia de Textos no 105). Lisboa: Ministério da Educação ; Direcção Geral dos Desportos

3. Doll-Tepper, G. (1995). Deporte para Atletas Disminuidos: Oportunidades de Hoy para una Vida mejor Mañana in: Instituto Andaluz del Deporte (Ed), Actas Congreso Científico Olímpico 1992: Actividad Física Adaptada, Psicología y Sociología (Deporte y Documentación, no 24 , volumen I). Málaga: Instituto Andaluz del Deporte, 25-39

4. Federação Portuguesa de Desporto para Deficientes (1995). Breve História das Organizações Desportivas. FPDD Informação, 7:7-17

5. Fernandes da Fonseca, A. ; Silva, A. (1998). A Perspectiva Biológica em Reabilitação Psicossocial: Modelos

Psicoterapêuticos de Intervenção em Reabilitação Psicossocial. Comunicação Apresentada in: Congresso Internacional de Reabilitação Psicossocial: Psicofarmacologia e Intervenção Comunitária. Porto: Serviço de Terapia Ocupacional e Reabilitação do Hospital de Magalhães Lemos (in press) 6. Kirk, S. ; Gallagher, J. (1979). Educating Exceptional Children ( $\left.3^{\mathrm{a}} \mathrm{ed}\right)$. Boston: Houghton Mifflin Company 7. Leitão, F. (1980). Algumas Perspectivas Históricas sobre Educação Especial. Ludens, 4(3):12-18

8. Lindstrom, H. (1986). Philosophy of Sports for the Disabled in: Vermeer, A. (Ed), Sports for the Disabled - Respo 86. Arnhem: Uitgeverij de Vrieseborch, 89-100

9. Lowenfeld, B. (1973). History of the Education of Visually Handicapped Children in: Lowenfeld, B. (Ed), The Visually Handicapped Child in School. New York: American Foundation for the Blind, 1-25

10. Mayor, F. (1994). Declaração de Salamanca. Conferência
Mundial Sobre Necessidades Educativas Especiais: Acesso e Qualidade. Paris: UNESCO

11. Mikkelsen, N. (1978). Misconceptions of the Principle of Normalization in Flash on the Service for the Mentally Retarded. Copenhagen: The Personal Training School

12. Organisation Mondiale de la Santé (1980). Classification Internationale des Handicaps: Déficiences, Incapacités et Désavantages. Paris: Éditions Inserm

13. Pereira, L. (1984). Evolução Histórica da Educação Especial in: Departamento de Educação Especial e Reabilitação (Ed),

Deficiência e Motricidade Terapêutica. Lisboa: ISEF-UTL, 37-51

14. Potter, J.C. (1981). Sport pour les Handicapés -

Contribution à l'Année Internationale des Handicapés.

Strasbourg: Comité pour le Développement du Sport ; Conseil de l'Europe

15. Rehabilitation International (1981). Charter for the 80's. New York: Rehabilitation International

16. Silva, A. (1991). Desporto para Deficientes: Corolário de uma Evolução Conceptual (Dissertação Apresentada às Provas de Aptidão Pedagógica e Capacidade Científica). Porto:

Faculdade de Ciências do Desporto e de Educação Física -

Universidade do Porto

17. Sousa, C. (1991). A Deficiência e a Solidariedade Social in: Secretaria Regional da Saúde e Segurança Social da Região Autónoma dos Açores (Ed), I Jornadas de Solidariedade Social dos Açores. Angra do Heroísmo: Secretaria Regional da Saúde e Segurança Social da Região Autónoma dos Açores, 81-90 18. Storm, A. (1980). Activites Sportives et Handicap. Sport, $1(89): 2-10$

19. UNESCO (1977). Glossary of Special Education Terms. Paris: UNESCO

20. Wolfensberger, W. (1972). The Principle of Normalization in Human Services. Toronto: National Institute on Mental Retardation 